\title{
(6) OPEN ACCESS \\ A novel multipatient intranasal diamorphine spray for use in acute pain in children: pharmacovigilance data from an observational study
}

\author{
Jason Kendall, ${ }^{1}$ Ian Maconochie, ${ }^{2}$ lan C K Wong, ${ }^{3,4}$ Richard Howard, ${ }^{5}$ \\ on behalf of the DIASAFE study
}

${ }^{1}$ Emergency Department, Frenchay Hospital, Bristol, UK ${ }^{2}$ Emergency Department, St Mary's Hospital, London, UK ${ }^{3}$ Therakind Ltd, London, UK

${ }^{4}$ Centre for Paediatric Pharmacy Research, UCL School of Pharmacy, University College London, London, UK

${ }^{5}$ Great Ormond Street Hospital, London, UK

\section{Correspondence to}

Dr Jason Kendall, Emergency Department, Frenchay Hospital, Frenchay Park Road, Bristol BS16 1LE, UK; jason.kendall@nbt.nhs.uk

Received 19 September 2013 Revised 18 November 2013 Accepted 23 November 2013 Published Online First 9 January 2014

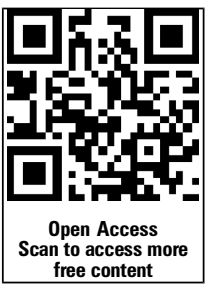

ABSTRACT
Objectives To establish the safety of an intranasal

diamorphine (IND) spray in children.

Design An open-label, single-dose pharmacovigilance trial.

Setting Emergency departments in eight UK hospitals. Participants Children aged 2-16 years with a fracture or other trauma.

Outcome measures Adverse events (AE) specifically related to nasal irritation, respiratory and central nervous system depression.

Results 226 patients received $0.1 \mathrm{mg} / \mathrm{kg}$ IND. No serious or severe AEs occurred. The incidence of treatment-emergent AEs (TEAEs) was $26.5 \%(95 \% \mathrm{Cl}$ $20.9 \%$ to $32.8 \%$ ), $93 \%$ being mild. $89 \%$ were related to treatment, all being known effects of the drug or route of administration except for three events in two patients. $20.4 \%$ (95\% Cl $15.3 \%$ to $26.2 \%)$ patients reported nasal irritation, all mild except one moderate and one 'unknown' severity. No respiratory depression was reported. Three AEs related to reduced Glasgow Coma Score (GCS) occurred, all mild.

Conclusions There were no safety concerns raised during the conduct of the study. In addition to expected side effects, IND can cause mild nasal irritation in a proportion of patients.

European Union Drug Regulating Authorities Clinical Trial No 2009-014982-16.

\section{INTRODUCTION}

Urgent pain relief is required for children presenting with fractures and burns in the emergency department (ED). Simple analgesics (eg, paracetamol) are insufficient to relieve severe pain; opiate analgesia is usually needed. Oral opiates are inappropriate due to delayed gastric emptying and slow onset of action; rapid routes of administration are necessary in the acute setting (ie, intravenous and intranasal delivery).

Diamorphine is a semisynthetic derivative of morphine that is licensed for moderate to severe acute pain, usually administered by the intramuscular or intravenous routes in the UK and Ireland. Diamorphine has properties that render it suitable for administration via the nasal route. ${ }^{1}$ First, it has good aqueous solubility, so a high dose can be given in a small volume thus avoiding swallowing excess solution which then enters the first-pass enterohepatic cycle of metabolism. Second, it is a highly lipid soluble which provides a rapid onset of action, as it crosses the blood-brain barrier more readily than morphine. Diamorphine is a prodrug

\section{Key messages}

What is known on this subject

- Intranasal diamorphine has an established role in the treatment of children presenting to the emergency department with acute moderate to severe pain.

- Its use is recommended in guidelines produced by the College of Emergency Medicine and the Advanced Paediatric Life Support Group.

- At the time of the study diamorphine did not have a licence for use as a nasal spray

What this study adds

- This paper reports data from a formal pharmacovigilance trial of a new intranasal diamorphine spray, Ayendi, used in children presenting to the emergency department with injuries requiring immediate pain relief.

- There were no serious or severe adverse events amongst 226 children who received $0.1 \mathrm{mg} / \mathrm{kg}$ intranasal diamorphine. The overall incidence of adverse events was $26.5 \%$, $93 \%$ of which were mild. $20.4 \%$ of patients reported nasal irritation.

- Nasal diamorphine spray shows a good safety profile when used as an analgesic agent for acute moderate to severe pain in children presenting to the emergency department and has been subsequently licensed in the UK for acute severe pain in children.

of morphine which induces more rapid and more intense central nervous system effects. ${ }^{12}$

Following initial efficacy studies ${ }^{3}{ }^{4}$ it has become common practice in the UK to administer intranasal diamorphine (IND) to children at a dose of $0.1 \mathrm{mg} /$ $\mathrm{kg}$ to relieve acute pain in the ED..$^{5-7}$ The College of Emergency Medicine and Advanced Paediatric Life Support Guidelines recommend this practice, ${ }^{89}$ and it is a treatment option in the British National Formulary for Children. ${ }^{10}$ Currently, IND is used off-label for children in approximately 55\% of EDs in the UK, ${ }^{6}$ usually between 3 years and 12 years of age. Although there are randomised and openlabel studies to demonstrate the efficacy of IND use in children, IND has never been licensed as a medicinal product. Consequently, systematic evaluation of safety data of IND use in children are still lacking. 
We report a large formal safety study of a diamorphine hydrochloride nasal spray.

\section{METHODS}

Design

The DIAmorphine SAFEty (DIASAFE) study was a multicentre, open-label, single-dose, pharmacovigilance study in children in the ED (recruiting April 2010-September 2011).

The study was approved by the regulatory authority and appropriate research ethics committees. Eight EDs took part in the safety study (see acknowledgements).

\section{Population}

Patients aged between 2 years and $<16$ years, weighing between $12 \mathrm{~kg}$ and $50 \mathrm{~kg}$, with a suspected clinical fracture, or other trauma requiring immediate pain relief with IND (in accordance with usual practice).

Patients accompanied by a consenting parent or guardian were eligible. Written informed consent was obtained from a parent or guardian. Oral or written assent was also obtained from the patient if the child was able (generally over 7 years). An additional summary consent form was used to avoid delay in provision of analgesia. Medical history, prior and current medications were recorded in each study.

Exclusion criteria included the presence of respiratory or airways problems, history of epistaxis, head injury, opioid analgesia or drugs known to interact with diamorphine in the preceding 7 days, or contraindications to the medication or excipients.

\section{Treatment}

The product (Ayendi) comprises diamorphine hydrochloride BP presented as a white freeze-dried powder in a vial (device bottle), together with separate diluent for reconstitution (preserved $0.5 \%$ saline). The nasal spray is designed as a multiuse product with replacement of the paediatric tip and priming between patients. The diamorphine is delivered at a single dose of $0.1 \mathrm{mg} / \mathrm{kg} \pm 20 \%$, using a total of $2-4$ actuations of the appropriate product strength directed into alternate nostrils, according to weight. It is provided in two strengths: $144 \mathrm{mg}$ and $320 \mathrm{mg}$, providing $720 \mu \mathrm{g}$ and $1600 \mu \mathrm{g}$ diamorphine hydrochloride per actuation $(50 \mu \mathrm{L})$, respectively, following reconstitution. The maximum volume administered per nostril is $100 \mu \mathrm{L}$; the maximum total dose is $4.8 \mathrm{mg}$ diamorphine hydrochloride (three sprays of $1600 \mu \mathrm{g} /$ actuation product). The small nasal volume administered ensures that absorption of the whole dose occurs transmucosally in the nares.

Each study site was provided with the two product strengths in vials together with diluent. The diluent was added to the bottle, the nasal spray pump (with paediatric nasal tip) attached, and devices were prepared for initial use by priming the spray eight times. Once reconstituted, sprays were stable at room temperature and could remain in the controlled drug cabinet for up to 14 days for multipatient use. A new paediatric tip was used for each patient, with the spray being primed twice between patients. Additional pain relief was allowed and was recorded.

\section{Outcome measures}

The primary outcome measures were observations related to the safety of IND, with particular focus on nasal irritation, sedation, central nervous system adverse events (AEs) and depression of respiration.

Vital signs (oxygen saturation levels, RR, heart rate), pupil dilation and Glasgow Coma Score (GCS) were recorded just before treatment, and the nasal cavities were examined for signs of abnormality. Vital signs (as above) and GCS were then measured immediately after diamorphine administration, at $15 \mathrm{~min}$ intervals for the first hour, and then every $30 \mathrm{~min}$ throughout the study. The nasal cavities were assessed for signs of nasal irritation every $30 \mathrm{~min}$ following diamorphine administration. All treatment-emergent AEs (TEAEs) were recorded throughout the child's participation in the study, and for 7 days postdosing (if reported to research staff spontaneously). All medication given (including additional analgesia) was recorded throughout the study duration.

\section{Safety and quality assurance}

An independent Data Safety Monitoring Committee reviewed safety data after inclusion of 50 children and had oversight for ongoing safety. The study was performed in compliance with Good Clinical Practice Guidelines.

\section{Statistical analysis}

The data analysis and statistics reporting was conducted using SAS V.9.2 (SAS Institute). All children who entered the study and were treated were included in the safety analyses. Summary statistics for quantitative data were produced, and for categorical data, frequency tables were generated. Data were summarised overall and by age group ( $2-11$ years; $12-<16$ years) as appropriate. Previous and concomitant medications were coded using the World Health Organisation Drug Dictionary coding system. AEs were coded using the MedDRA dictionary (V.13.0) and relationship (causality), and severity of all events was evaluated using WHO toxicity criteria. Serious AEs were classified according to the Medicines and Healthcare Regulatory Agency's definition. Any events related to nasal irritation were specifically grouped, reported separately and classified by type of irritation (persistent and troublesome sneezing, redness, itching, local tenderness, swelling, nasal discharge or 'other') and severity.

In order to provide $95 \%$ confidence of detecting reactions occurring with $>2 \%$ frequency, a minimum number of 150 children was required.

\section{RESULTS}

\section{Study population}

Two hundred and twenty-six patients were recruited into DIASAFE between April 2010 and September 2011, all of whom received IND. One child was withdrawn from the study due to rapid transfer to theatre for surgery, making further observations impossible. Two hundred and twenty-five (191 aged 2-11 years, and 34 aged $12-<16$ years) completed the study. Table 1 shows the characteristics of children included. For a number of children (56) study staff failed to follow study protocol (the majority (36) of which were due to insufficient safety observations); this was anticipated in the emergency setting and was reflected in the study sample size (226), with over 150 children completed without major protocol deviation.

The majority of children attended with fractures (80\%), most of which were upper limb fractures. Burn injury was less frequent (7\%). Other presentations included amputation/partial amputation, laceration and dislocation. A small number of children had a history of previous medical problems, but none were considered to be clinically relevant to the study.

Tables 2 and 3 show concomitant medication administered before and during the DIASAFE study data collection period, respectively. 
Table 1 Characteristics of the children in the DIASAFE study

\begin{tabular}{|c|c|c|c|}
\hline Statistics & $\begin{array}{l}\text { Age group } \\
2-11 \text { years } \\
(\mathrm{N}=191)\end{array}$ & $\begin{array}{l}\text { Age group } \\
12-<16 \text { years } \\
(\mathrm{N}=35)\end{array}$ & $\begin{array}{l}\text { Overall } \\
(\mathrm{N}=226)\end{array}$ \\
\hline \multicolumn{4}{|l|}{ Age (years) } \\
\hline Mean & 6.6 & 12.9 & 7.6 \\
\hline SD & 2.91 & 0.89 & 3.54 \\
\hline Minimum & 1 & 12 & 1 \\
\hline Median & 6.0 & 13.0 & 7.0 \\
\hline Maximum & 11 & 15 & 15 \\
\hline \multicolumn{4}{|l|}{ Gender $\mathrm{n}(\%)$} \\
\hline Male & $110(57.6)$ & $27(77.1)$ & $137(60.6)$ \\
\hline Female & $81(42.4)$ & $8(22.9)$ & $89(39.4)$ \\
\hline \multicolumn{4}{|l|}{ Race n (\%) } \\
\hline White & $169(88.5)$ & $31(88.6)$ & $200(88.5)$ \\
\hline Black & $5(2.6)$ & $2(5.7)$ & $7(3.1)$ \\
\hline Asian & $6(3.1)$ & $2(5.7)$ & $8(3.5)$ \\
\hline Other & $7(3.7)$ & 0 & $7(3.1)$ \\
\hline Unknown & $4(2.1)$ & 0 & $4(1.8)$ \\
\hline \multicolumn{4}{|l|}{ Weight (kg) } \\
\hline Mean & 26.46 & 43.01 & 29.03 \\
\hline SD & 9.64 & 5.58 & 10.92 \\
\hline Minimum & 12.0 & 30.6 & 12.0 \\
\hline Median & 24.00 & 43.30 & 26.60 \\
\hline Maximum & 50.0 & 50.5 & 50.5 \\
\hline \multicolumn{4}{|c|}{ Nasal application site $\mathrm{n}(\%)$} \\
\hline Normal & $189(99.0)^{*}$ & $35(100.0)$ & $224(99.1)^{*}$ \\
\hline Abnormal & 0 & 0 & 0 \\
\hline \multicolumn{4}{|c|}{$\begin{array}{l}(\%)=\mathrm{n} / \mathrm{N} \times 100 \text { for categorical variables. } \\
\text { *In two children, there was no recording of nasal application site (no adverse events } \\
\text { related to nasal irritation in these children). } \\
\mathrm{N} \text {, the number of patients in the population. } \\
\mathrm{n} \text {, the number of patients meeting the criterion. }\end{array}$} \\
\hline
\end{tabular}

\section{Safety}

\section{Adverse events}

There were 87 TEAEs reported by 60 patients with $26.5 \%$ (95\% CI $20.9 \%$ to $32.8 \%$ ) of patients reporting one or more events, $25.1 \%$ of the younger children (2-11 years), and $34.3 \%$ of the older children $(12-<16)$ (table 4). No events were severe or serious. Most AEs were mild (93\%) except five moderate AEs in three patients (all resolved by discharge) and one event not given a severity rating (resolved by discharge).

The most common events involved the respiratory system (53 events in 45 children) including nasal discomfort ( 24 children) and sneezing (22 children). Nervous system disorders were

Table 2 Children given medicines before receiving IND in the DIASAFE STUDY

\begin{tabular}{lll}
\hline Medications & $\begin{array}{l}\text { No. of } \\
\text { patients }\end{array}$ & $\begin{array}{l}\text { Percentage of total } \\
\text { patients* (\%) }\end{array}$ \\
\hline Patients given medication prior to IND & 136 & 60.2 \\
Painkillers & & \\
$\quad$ Paracetamol & 117 & 51.8 \\
Ibuprofen & 92 & 40.7 \\
$\quad$ Entonox & 36 & 15.9 \\
$\quad$ Oramorph & 5 & 2.2 \\
\hline *To 1 decimal place. & & \\
IND, intranasal diamorphine. & & \\
\hline
\end{tabular}

Table 3 Children given concomitant medicines in the DIASAFE study

\begin{tabular}{lll}
\hline Concomitant Medications & $\begin{array}{l}\text { No. of } \\
\text { patients }\end{array}$ & $\begin{array}{l}\text { Percentage of total } \\
\text { patients* }\end{array}$ \\
\hline $\begin{array}{l}\text { Patients given medication post-IND } \\
\text { Painkillers }\end{array}$ & 100 & 44.4 \\
$\quad$ Paracetamol & 47 & 20.8 \\
$\quad$ Ibuprofen & 44 & 19.5 \\
Entonox & 20 & 8.8 \\
Diclofenac & 1 & 0.4 \\
$\quad$ Opiate (non-IMP) & 10 & 4.4 \\
Asthma treatment & & \\
Salbutamol & 6 & 2.7 \\
Beclometasone & 4 & 1.8 \\
$\quad$ Fluticasone & 1 & 0.4 \\
$\quad$ Antihistamine (chlorpheniramine) & 2 & 0.9 \\
Other & & \\
$\quad$ Topical/local anaesthetic & 7 & 3.1 \\
Antibiotic & 6 & 2.7 \\
Midazolam & 1 & 0.4 \\
Ketamine & 3 & 1.3 \\
\hline
\end{tabular}

*To 1 decimal place

IMP, investigational medicinal product; IND, intranasal diamorphine.

Table 4 DIASAFE adverse event overview

\begin{tabular}{|c|c|}
\hline Body system & $\begin{array}{l}\mathrm{N}=226 \\
\text { Total number of events (number } \\
\text { of patients) }\end{array}$ \\
\hline $\begin{array}{l}\text { Respiratory, thoracic and mediastinal } \\
\text { disorders }\end{array}$ & $53(45)$ \\
\hline Nervous system disorders & $15(11)$ \\
\hline Dysgeusia & 5 \\
\hline Dizziness & 4 \\
\hline Somnolence & 3 \\
\hline Paraesthesia mucosal & 2 \\
\hline Depressed level of consciousness & 1 \\
\hline Gastrointestinal disorders & $11(9)$ \\
\hline $\begin{array}{l}\text { General disorders and administration site } \\
\text { conditions }\end{array}$ & $3(3)$ \\
\hline Skin and subcutaneous tissue disorders & $2(2)$ \\
\hline Psychiatric disorders & $1(1)$ \\
\hline Anxiety & 1 \\
\hline Eye disorders & $1(1)$ \\
\hline Vascular disorders & $1(1)$ \\
\hline \multicolumn{2}{|l|}{$\begin{array}{l}\text { Injury, poisoning and procedural } \\
\text { complications }\end{array}$} \\
\hline \multirow{2}{*}{$\begin{array}{l}\text { Total number of events (number of } \\
\text { patients) }\end{array}$} & 87 Total \\
\hline & $\begin{array}{l}10 \text { Non-related* } \\
77 \text { Relatedt } \\
81 \text { Mild } \\
5 \text { Moderate } \\
0 \text { Severe } \\
1 \text { Unknown severity }\end{array}$ \\
\hline
\end{tabular}


Table 5 DIASAFE adverse events relating to nasal irritation

\begin{tabular}{|c|c|c|c|c|}
\hline Classification type & Severity* & $\begin{array}{l}\text { Age group 2-11 years }(\mathrm{N}=191) \\
\text { Patients }(\%)\end{array}$ & $\begin{array}{l}\text { Age group } 12-<16 \text { years }(\mathrm{N}=35) \\
\text { Patients }(\%)\end{array}$ & $\begin{array}{l}\text { Overall }(\mathrm{N}=226) \\
\text { Patients }(\%)\end{array}$ \\
\hline Patients with any nasal irritation TEAE & $\begin{array}{l}\text { Overall } \\
\text { Mild } \\
\text { Moderate } \\
\text { Severe } \\
\text { Unknown }\end{array}$ & $\begin{array}{c}38(19.9) \\
36(18.8) \\
1(0.5) \\
0 \\
1(0.5)\end{array}$ & $\begin{array}{l}8(22.9) \\
8(22.9) \\
0 \\
0 \\
0\end{array}$ & $\begin{array}{l}46(20.4) \\
44(19.5) \\
1(0.4) \\
0 \\
1(0.4)\end{array}$ \\
\hline Persistent and troublesome Sneezing & $\begin{array}{l}\text { Overall } \\
\text { Mild }\end{array}$ & $\begin{array}{l}5(2.6) \\
5(2.6)\end{array}$ & $\begin{array}{l}4(11.4) \\
4(11.4)\end{array}$ & $\begin{array}{l}9(4.0) \\
9(4.0)\end{array}$ \\
\hline Redness & $\begin{array}{l}\text { Overall } \\
\text { Mild }\end{array}$ & $\begin{array}{l}1(0.5) \\
1(0.5)\end{array}$ & $\begin{array}{l}0 \\
0\end{array}$ & $\begin{array}{l}1(0.4) \\
1(0.4)\end{array}$ \\
\hline Itching & $\begin{array}{l}\text { Overall } \\
\text { Mild } \\
\text { Moderate }\end{array}$ & $\begin{array}{c}20(10.5) \\
19(9.9) \\
1(0.5)\end{array}$ & $\begin{array}{l}2(5.7) \\
2(5.7) \\
0\end{array}$ & $\begin{array}{r}22(9.7) \\
21(9.3) \\
1(0.4)\end{array}$ \\
\hline Nasal discharge & $\begin{array}{l}\text { Overall } \\
\text { Mild }\end{array}$ & $\begin{array}{l}0 \\
0\end{array}$ & $\begin{array}{l}1(2.9) \\
1(2.9)\end{array}$ & $\begin{array}{l}1(0.4) \\
1(0.4)\end{array}$ \\
\hline Other-nasal discomfort & $\begin{array}{l}\text { Overall } \\
\text { Mild } \\
\text { Unknown }\end{array}$ & $\begin{array}{l}4(2.1) \\
3(1.6) \\
1(0.5)\end{array}$ & $\begin{array}{l}1(2.9) \\
1(2.9) \\
0\end{array}$ & $\begin{array}{l}5(2.2) \\
4(1.8) \\
1(0.4) \dagger\end{array}$ \\
\hline Other-sneezing & $\begin{array}{l}\text { Overall } \\
\text { Mild }\end{array}$ & $\begin{array}{l}11(5.8) \\
11(5.8)\end{array}$ & $\begin{array}{l}3(8.6) \\
3(8.6)\end{array}$ & $\begin{array}{l}14(6.2) \\
14(6.2)\end{array}$ \\
\hline Local tenderness & Overall & 0 & 0 & 0 \\
\hline Swelling & Overall & 0 & 0 & 0 \\
\hline
\end{tabular}

reported by 11 children, the most common being an unpleasant taste (five children). Nine children reported gastrointestinalrelated events (11 events, including vomiting in seven children).

The majority $(88.5 \%)$ of AEs (77 events in 54 children) were considered to be causally related to treatment, and were anticipated due to the drug itself or route of administration, with the exception of three events in two children: moderate itchy eyes in one child and mild pallor and 'feeling hot' in another.

The percentage of patients experiencing an $\mathrm{AE}$ was higher in the older age group than in the younger $(34.3 \%$ vs $25.1 \%)$.

Ten children experienced an AE after discharge from the ED, reporting 13 AEs, most of which (12) were mild. One child experienced moderate vomiting.

Any vital signs measure or reduction in GCS score that the investigator considered clinically relevant for the study was to be reported as an AE. No vital sign measures were reported as AEs.

Three children had AEs recorded that were associated with a decrease in GCS, all mild, and considered to be causally related to IND. All but one resolved within the study period, in this case the GCS value returned to normal at 50 min after dosing.

\section{Nasal tolerability}

There were $20.4 \%$ (95\% CI $15.3 \%$ to $26.2 \%$ ) of patients who reported at least one nasal AE, $19.9 \%$ of the younger children (2-11 years), and $22.9 \%$ of the older children $(12-<16$ years) (table 5). There were 52 mild, one moderate and one unclassified AEs related to nasal irritation reported by 46 children. The most common was itching reported by 22 patients, all considered to be mild except one (moderate). Persistent and troublesome sneezing (mild) was reported by nine patients. There were single reports of mild redness, and mild nasal discharge. The remainder of the events were classified as 'Other' (19 patients) which included instances of a single sneeze following administration. No patient reported local tenderness or swelling. No further nasal AEs were seen after discharge.

Most (45 out of $54(83.3 \%)$ ) nasal AEs occurred within $30 \mathrm{~min}$ of dosing, seven between $30 \mathrm{~min}$ and $1 \mathrm{~h}$, and two started beyond $1 \mathrm{~h}$ of dosing. Most events (76\%) resolved within $1 \mathrm{~h}$ (37\% within $5 \mathrm{~min})$, with $11 \%$ resolving later than $1 \mathrm{~h}$. The remaining 13\% had an unknown resolution time. The onset and resolution of AEs is consistent with the short half-life of diamorphine and its active metabolites.

The majority of patients reporting nasal events were treated with higher strength $(1600 \mu \mathrm{g} /$ actuation) spray (32 (70\%)). However, there was not an increased reporting rate in patients administered two sprays per nostril versus one spray per nostril.

\section{DISCUSSION}

The DIASAFE study was designed with sufficient sample size to ensure (with 95\% probability) that at least one child would experience any particular AE, if the underlying event rate was at least $2 \%$. As with other opiates, the main adverse effects of diamorphine include respiratory depression, sedation, nausea and vomiting, constipation and sweating. In this study, there was no evidence of clinically significant respiratory depression, and only minor reductions in the level of consciousness in children. The incidence of vomiting was as expected and considered to be acceptable.

A potential concern of IND is local (nasal) tolerability. No incidence of swelling or tenderness was seen, although a small number of children reported mild itching (with one moderate itching) or mild sneezing. Nasal irritation does not appear to be directly related to the volume administered per se, but just due 
to exposure to the product in those sensitive to the drug, excipients or nasal administration in general. The severity of irritation has been mild only, except for one moderately severe report, and one report which was not graded, but no sequelae were reported.

The incidence of AEs in the DIASAFE study (26.5\%) is similar to the Kendall study $(24.5 \%)^{11}$ which compared safety and efficacy of IND with intramuscular morphine sulfate; specific attribution of events was not recorded in this earlier study. The incidence of AEs related to nasal irritation, however, was higher in the DIASAFE study compared to the Kendall study ${ }^{11}(20.4 \%$ patients vs $13.2 \%$ ). This was expected, because nasal irritation was systematically evaluated in the DIASAFE study in line with study objectives. In the Kendall study, nasal irritation was assessed by staff at the time of treatment administration, and thereafter evaluated ad hoc by asking patients if they had irritation rather than specifically assessing the site of administration.

The DIASAFE study was carried out in Teaching and District General Hospital EDs, some of which had dedicated paediatric EDs, with varying local population catchment areas and characteristics. Thus, children in this trial are representative of those presenting to EDs throughout the UK. Our studies were unable to evaluate rare AEs due to the limited sample size.

\section{OVERALL CONCLUSION}

There were no safety concerns raised during the conduct of the study. In addition to the expected side effects of dose-related opioid sedation and gastrointestinal effects, IND can cause mild nasal irritation in a proportion of patients. A dose of $0.1 \mathrm{mg} / \mathrm{kg}$ appears appropriate in the ED setting. Overall diamorphine nasal spray shows a good safety profile.

Acknowledgements We thank the patients, parents and staff at the participating centres for both studies.

Collaborators DIASAFE: Vanessa Lawlor, Hannah Skuse, lan Gilmour, Charlotte Sykes, Dr Elizabeth Gilby, Angela Green, Kelly Davidson, Dr Tina Sajjanhar, Robert Cole, Prof Jonathan Benger, Dr Giles Haythornthwaite, Judith Edwards, Rebecca Ace, Marie Teresa-Marie Jones, Dr Cliff Mann, Sara Lees, Dr Sharryn Gardner, Zena Haslam, Moira Morrison, Anne Welling, Dr Joanna Hartley, Sarah Cooke. CENTRES: Frenchay Hospital, Bristol; St Mary's Hospital, London; Royal United Hospital, Bath; University Lewisham Hospital, Lewisham; Bristol Royal Hospital for Children, Bristol; Musgrove Park Hospital, Taunton; Ormskirk and District General Hospital, Ormskirk; Queen Alexandra Hospital, Portsmouth.

Contributors JK participated in the design, recruitment and clinical aspects of the study. IM participated in the design, recruitment and clinical aspects of the study. ICKW contributed to the conception of the project and participated in the design of the study. RH participated in the design of the study.

All authors contributed to the writing of the paper and will act as guarantors.
Funding Wockhardt UK Ltd sponsored the study. Study Management by Therakind Ltd.

Competing interests All authors have completed the ICMJE uniform disclosure form at (http://www.icmje.org/coi_disclosure.pdf) and declare: financial support for conduct of the clinical trials was provided by Wockhardt UK Ltd (sponsor); JK and RH have no financial relationships with any organisations that might have an interest in the submitted work in the previous 3 years, IM has worked as a consultant to Therakind Ltd and ICKW is a director of Therakind Ltd; no other relationships or activities that could appear to have influenced the submitted work.

\section{Patient consent Obtained.}

Ethics approval North Somerset and South Bristol Research Ethics Committee. Provenance and peer review Not commissioned; externally peer reviewed.

Open Access This is an Open Access article distributed in accordance with the Creative Commons Attribution Non Commercial (CC BY-NC 3.0) license, which permits others to distribute, remix, adapt, build upon this work non-commercially, and license their derivative works on different terms, provided the original work is properly cited and the use is non-commercial. See: http://creativecommons.org/ licenses/by-nc/3.0/

\section{REFERENCES}

1 Rook EJ, van Ree JM, Hillebrand MJX, et al. Pharmacokinetics and pharmacodynamics of high doses of pharmaceutically prepared heroin, by intravenous or by inhalation route in opioid-dependent patients. Basic Clin Pharmacol Toxicol 2006;98:86-96.

2 Mondzac AM. In defense of the reintroduction of heroin into American Medical practice and H.R.5290 — the compassionate pain relief act. N Engl J Med 1984;311:532-5.

3 Wilson JA, Kendall JM, Cornelius P. Intranasal diamorphine for paediatric analgesia: assessment of safety and efficacy. J Accident Emerg Med 1997;14:70-2.

4 Kendall JM, Reeves BC, Latter VS, Nasal Diamorphine Group. Multicentre randomised controlled trial of nasal diamorphine for analgesia in children and teenagers with clinical fractures. BMJ 2001;322:261-5.

5 Hadley G, Maconochi I, Jackson A. A survey of intranasal medication use in the paediatric emergency setting in England and Wales. Emerg Med J 2010;27:553-4.

6 Kerr M, Maconochi I. Intranasal diamorphine usage in paediatric accident and emergency. Curr Padiatr Rev 2010;6:151-5.

7 Loryman B, Davies F, Chavada G, et al. Consigning "brutacaine" to history: a survey of pharmacological techniques to facilitate painful procedures in children in emergency departments in the UK. Emerg Med J. 2006;23:838-40.

8 College of Emergency Medicine Clinical Effectiveness Committee. Guideline for the management of pain in children. May 2010. http://www.collemergencymed.ac.uk/ Shop-Floor/Clinical\%20Guidelines/Clinical\%20Guidelines/default.asp (accessed 2 Jul 2013).

9 Advanced Life Support Group. Advanced Paediatric Life Support: the Practical Approach (APLS). 5th edn. BMJ Books, 2011:310.

10 British National Formulary for Children. The essential resource for clinical use of medicines in children. BMJ Group RPS Publishing RCPCH Publications Ltd, 2011.

11 Unreported data: Randomised, controlled, one-way blinded multicentre study comparing nasal diamorpine hydrochloride with intramuscular morphine sulpate for emergency analgesia in children presenting to the A\&E department with clinical fractures. Wockhardt UK Ltd (CP Pharmaceuticals). 1999. 